\title{
Novel NADPH oxidase inhibitor VAS2870 suppresses

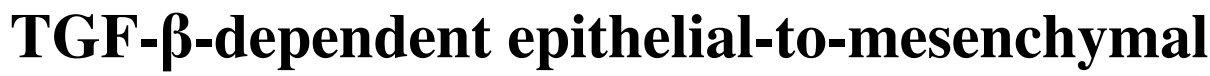 transition in retinal pigment epithelial cells
}

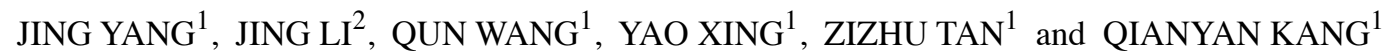 \\ ${ }^{1}$ Department of Ophthalmology, The First Affiliated Hospital of Medical School of Xi'an Jiaotong University, Xi'an, \\ Shaanxi 710061; ${ }^{2}$ Department of Ophthalmology, Shaanxi Provincial People's Hospital, Xi'an, Shaanxi 710068, P.R. China
}

Received October 3, 2017; Accepted March 27, 2018

DOI: $10.3892 /$ ijmm.2018.3612

\begin{abstract}
NADPH oxidases (NOXs) are important in the pathophysiology of fibrotic diseases. The expression and activity of NOXs are regulated by growth factors, including transforming growth factor (TGF- $\beta$ ). The proliferation of retinal pigment epithelial (RPE) cells following epithelial- to-mesenchymal transition (EMT) is a major pathological change involved in proliferative vitreoretinopathy (PVR). The aim of the present study was to determine the effects of the novel NOX inhibitor VAS2870 on the TGF- $\beta$-dependent expression of NOX4 and associated cellular events in RPE cells. Cell viability was examined using a Cell Counting Kit- 8 assay and cell cycle progression was detected by flow cytometric analysis. Immunofluorescence analysis and western blot analysis were performed to assess EMT. It was found that TGF- $\beta$ increased the expression of NOX4 and that pre-incubation with VAS2870 eliminated this effect. Additionally, TGF- $\beta$ promoted RPE migration and increased EMT. Pre-incubation with VAS2870 significantly prevented TGF- $\beta 2$-induced EMT by decreasing the levels of $\alpha$-smooth muscle actin and E-cadherin, and also inhibited the migratory ability of the RPE cells, as demonstrated by scratch assays. Finally, VAS2870 suppressed the proliferation of RPE cells, and led to $G_{1}$-phase cell cycle arrest and a significant downregulation of the expression of cyclin D1. In conclusion, the pharmacological inhibition of NOX may be a promising tool for the treatment of PVR.
\end{abstract}

Correspondence to: Dr Qianyan Kang, Department of Ophthalmology, The First Affiliated Hospital, Medical School of Xi'an Jiaotong University, 76 Yanta West Road, Xi'an, Shaanxi 710061, P.R. China

E-mail: kangqy@xjtu.edu.cn

Key words: VAS2870, NADPH oxidase 4, proliferation, epithelialto-mesenchymal transition, retinal pigment epithelial cells, proliferative vitreoretinopathy, $\alpha$-smooth muscle actin, cyclin D1, E-cadherin

\section{Introduction}

Proliferative vitreoretinopathy (PVR) is a complication of retinal detachment $(\mathrm{RD})$ and is the primary cause of surgical failure following RD treatment (1). PVR is characterized by the formation of fibrotic tissue on the detached retina, which hinders retinal reattachment and can potentially cause blindness (2). Surgical removal of the fibrotic membranes by retinal repair is the primary treatment for PVR. The pathology of the fibrotic membrane reflects an excessive wound healing reaction characterized by cell proliferation, migration, extracellular matrix (ECM) production and remodeling (3). For these reasons, the identification of novel treatments to improve the available therapeutic options is essential for managing this disease.

Retinal pigment epithelial (RPE) cells are a major component of the fibrotic membrane; these cells transform into fibroblast-like cells through epithelial-to-mesenchymal transition (EMT) (4). Under normal, healthy conditions, RPE cells form a monolayer comprising the blood-retina barrier between the retina and choroid (5). During EMT, RPE cells lose their epithelial characteristics, including unique cell-to-cell contact, and obtain mesenchymal properties (6). In addition, the RPE cells proliferate, migrate towards the vitreous body or intraretinal layers, and produce ECM, leading to the formation of fibrotic membranes (7). However, the specific molecular mechanisms mediating these processes remain to be fully elucidated, and an effective therapeutic approach targeting RPE cells has not been developed.

NADPH oxidases (NOXs) are a family of heme-containing proteins, the main function of which is the production of reactive oxygen species. A total of seven NOX proteins have been identified, including NOX1-5 and DUOX1-2. These enzymes are widely expressed in numerous tissues and have various functions, including roles in cell signaling, regulation of gene expression, cell death, cell differentiation, and growth (8). The expression and activity of these enzymes are regulated by growth factors, including angiotensin II, platelet-derived growth factor and transforming growth factor (TGF)- $\beta$ (9). Among these, TGF- $\beta$ initiates the upregulation of other PVR-inducing factors. The major TGF- $\beta$ isoform in the posterior segment of the eye, TGF- $\beta 2$, is overexpressed 
in the vitreous and proliferative membranes of patients with PVR $(10,11)$.

A previous study showed that RPE cells express NOX1, NOX2 and NOX4 under normal physiological conditions (12). NOX4 is a 578-amino acid flavocytochrome protein with six transmembrane domains, which has been shown to modulate epithelial cell cytoskeletal alterations, smooth muscle cell differentiation, pulmonary fibroblast proliferation, and liver fibrosis (13-16). NOXs are involved in the development and progression of a wide spectrum of diseases and represent a significant therapeutic target. However, the majority of NOX inhibitors have not demonstrated sufficient clinical efficacy. For example, apocynin affects other events, including the induction of transcription factor activator protein-1 (17) and the formation of thromboxane A2, which is independent of NOXs (18). In addition, diphenyleneiodonium is not specific for NOXs as it inhibits all flavoenzymes, including xanthine oxidase and cytochrome P450 (19).

Accordingly, the present study aimed to investigate the effects of a novel NOX inhibitor, VAS2870, which is the only confirmed low-molecular-weight pharmacological inhibitor of NOX, on the TGF- $\beta$-dependent expression of NOX4, migration, EMT and cell proliferation in RPE cells. The findings may provide important insights into the potential application of NOX inhibitors for the treatment and prevention of PVR.

\section{Materials and methods}

RPE cell culture and treatment. The ARPE-19 human RPE cells were obtained from the American Type Culture Collection (Manassas, VA, USA). The ARPE-19 line is an immortalized cell line, which spontaneously arose from cultures of human RPE. The cells were cultured in Dulbecco's modified Eagle's medium (DMEM)/F12 containing 10\% fetal bovine serum (Gibco; Thermo Fisher Scientific, Inc., Waltham, MA, USA). The cells were cultured to $70 \%$ confluence at $37^{\circ} \mathrm{C}$ in a humidified atmosphere containing $5 \% \mathrm{CO}_{2}$, and the medium was replaced every 2-3 days. Subsequently, the cells were disaggregated with $0.25 \%$ trypsin- $0.02 \%$ ethylenediaminetetraacetic acid solution and were passaged every 3-5 days. The cells were randomly divided into five groups: Control, $5 \mathrm{ng} / \mathrm{ml}$ TGF- $\beta 2$, TGF- $\beta 2+1 \mu \mathrm{M} / \mathrm{ml}$ VAS2870, TGF- $\beta 2+3 \mu \mathrm{M} / \mathrm{ml}$ VAS2870, and TGF- $\beta 2+5 \mu \mathrm{M} / \mathrm{ml}$ VAS2870. TGF- $\beta 2$ and VAS2870 were purchased from Sigma-Aldrich; Merck KGaA (Darmstadt, Germany).

Reverse transcription-quantitative polymerase chain reaction (RT-qPCR) analysis. Total RNA was isolated using an RNA extraction kit (Fastagen Biotech, Shanghai, China) and reverse transcribed into complementary DNA (cDNA) using a PrimerScript First Strand cDNA Synthesis kit (Takara Biotechnology Co., Ltd., Shiga, Japan) according to the manufacturer's protocol. The quality of the RNA samples was controlled by measuring the absorbance at A260/280; an absorption between 1.8 and 2.1 indicated that the RNA was of high quality. For PCR amplification, a MyTaq Red DNA Polymerase (Bioline, London, England) kit was used according to the manufacturer's protocol (10 $\mu \mathrm{l}$ 5xMyTaq Red Reaction buffer, forward and reverse primers $(20 \mu \mathrm{M})$, each $1 \mu \mathrm{l}, 1 \mu \mathrm{l}$ MyTaq Red DNA polymerase, $10 \mathrm{ng}$ cDNA and up to $50 \mu \mathrm{l}$
$\left.\mathrm{ddH}_{2} \mathrm{O}\right)$. The primers used for detection of mRNA expression of NOX1-4 and GAPDH were based on previously published sequences (12). For quantitative detection of NOX1-4 mRNAs, the following sequence-specific primers were used: $N O X 1$, forward 5'-TTCACCAATTCCCAGGATTGAAGTGGATGG TC-3' and reverse 5'-GACCTGTCACGATTGCATGGCCTT GTCAA-3'; NOX2, forward 5'-AGAGGGTTGGAGGTGGAG AATT-3' and reverse 5'-GCACAAGGAGCAGGACTAGAT GA-3'; NOX4, forward 5'-CTGGAGGAGCTGGCTCGCCAA CGAAG-3' and reverse 5'-GTGATCATGAGGAATAGCACC ACCACCATGCAG-3'; GAPDH, forward 5'-UUCUCCGAA CGUGUCACGUTT-3' and reverse 5'-ACGUGACACGUU CGGAGAATT-3'. The PCR was performed as follows: $30 \mathrm{sec}$ at $95^{\circ} \mathrm{C}$, followed by 40 cycles of $5 \mathrm{sec}$ at $95^{\circ} \mathrm{C}, 20 \mathrm{sec}$ at $60^{\circ} \mathrm{C}$ and $20 \mathrm{sec}$ at $72^{\circ} \mathrm{C}$. The amplified DNA was visualized with SYBR Safe DNA Gel staining (diluted to 1:10,000; Invitrogen; Thermo Fisher Scientific, Inc.) on 3\% agarose TAE gels run at $100 \mathrm{~V}$ for $30 \mathrm{~min}$. Positive control tissues for each NOX homolog were also examined (human NOX1, NOX2 and NOX4). It was not possible to validate the expression of NOX3 as it is predominantly expressed in the inner ear. The gene expression levels were normalized to the endogenous control GAPDH, and fold changes were calculated using the $2^{-\Delta \Delta C q}$ method (20). All PCR reactions were performed at least in triplicate.

Cell Counting Kit-8 (CCK-8) assays. Cell viability was examined using CCK-8 assays (7Sea Pharmatech, Co., Ltd., Shanghai, China). VAS2870 (Sigma-Aldrich; Merck KGaA) was diluted in dimethylsulfoxide (DMSO; Sigma-Aldrich; Merck KGaA) to different concentrations. The RPE cells were plated in 96 -well plates $\left(5 \times 10^{3}\right.$ cells/well) with $100-\mu 1$ complete culture medium. The cells were then treated with $0.1,0.5,1,5$ or $10 \mu \mathrm{M} / \mathrm{ml}$ VAS2870 (dissolved in DMSO). After 24,48 or $72 \mathrm{~h}, 10 \mu \mathrm{l}$ CCK-8 solution was added to each well, and the plates were incubated for $2 \mathrm{~h}$ at $37^{\circ} \mathrm{C}$. The absorbance was determined at $450 \mathrm{~nm}$ with a microplate reader (Epoch; Bio-Tek Instruments Inc., Winooski, VT, USA).

Wound healing assays. The RPE cells were seeded in 6-well cell culture plates at a concentration of $5 \times 10^{5}$ cells/well, grown to almost $100 \%$ confluence as a monolayer and then incubated with serum-free DMEM. Wounds were gently introduced in the center of the well using a sterile $200-\mu 1$ pipette tip, following which the plates were washed with phosphate-buffered saline (PBS) to remove cell debris. TGF- $\beta 2(5 \mathrm{ng} / \mathrm{ml})$ and VA2870 $(5 \mu \mathrm{M})$ were then added to the cells. Images of marked regions along the wound region were captured using an inverted phase contrast microscope (Leica DMI3000B; Leica Microsystems $\mathrm{GmbH}$, Asslar, Germany) immediately following creation of the wound. The distance migrated by the RPE cells into the wounded region was determined by collecting images every $24 \mathrm{~h}$.

Cell cycle analysis. The RPE cells were seeded in $25-\mathrm{cm}^{2}$ culture flasks at a density of $1 \times 10^{6}$ cells/flask. The cells were starved overnight and divided into four groups (control group, and 1,3 , and $5 \mu \mathrm{M}$ VAS2870 groups). Following incubation at $37^{\circ} \mathrm{C}$ for $24 \mathrm{~h}$, the cells were collected and fixed in $70 \%$ 
A

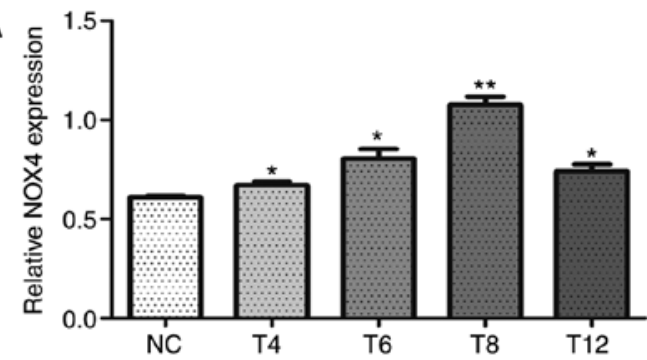

NOX4

$\beta$-actin

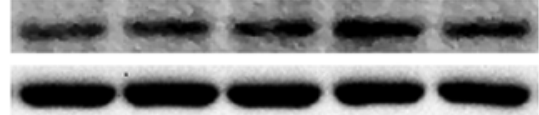

C
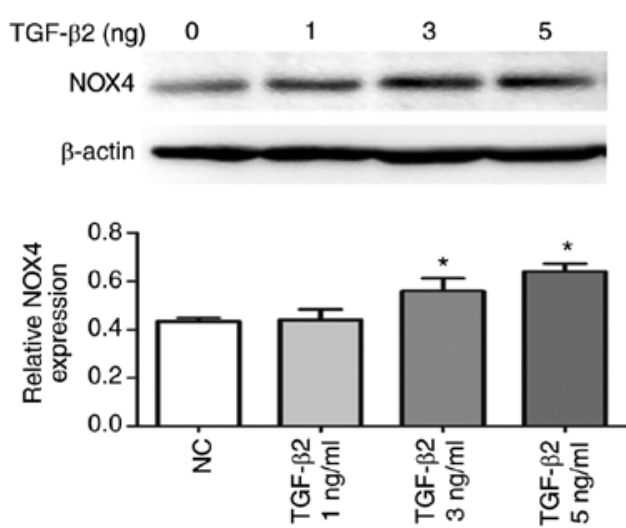

B
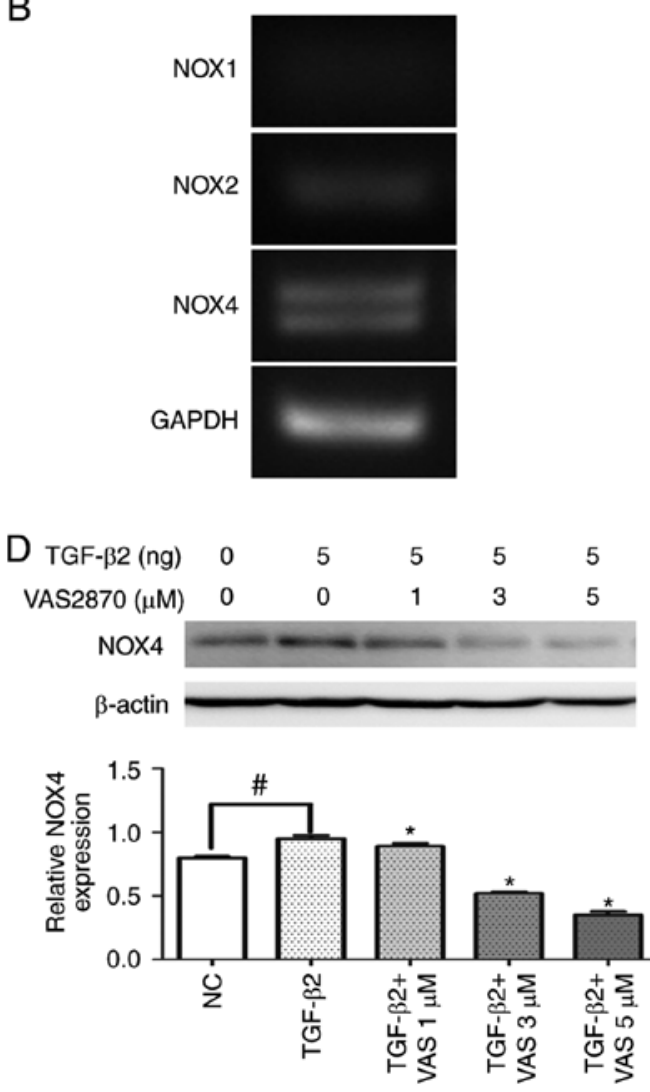

Figure 1. VAS2870 suppresses the TGF- $\beta 2$-induced activated expression of NOX4. (A) Representative western blots depicting the time-course (4, 6, 8 and $12 \mathrm{~h}$ ) of the expression of NOX4 following TGF- $\beta 2$ treatment, compared with that in control explants. ${ }^{*} \mathrm{P}<0.05$ and ${ }^{* * *} \mathrm{P}<0.01$, vs. NC group. (B) Representative results of reverse transcription-quantitative PCR analysis of $N O X 1, N O X 2$ and NOX4 mRNA transcripts after $8 \mathrm{~h}$. For each lane, the PCR products shown correspond to the expected base pair lengths (NOX1, $62 \mathrm{bp}$; NOX2, $45 \mathrm{bp} ; N O X 4,59 \mathrm{bp}$; GAPDH, $42 \mathrm{bp}$ ). (C) Changes in the expression of NOX4 in the presence of 1,3 and $5 \mathrm{ng} / \mathrm{ml}$ TGF- $\beta 2$ for $24 \mathrm{~h}$. ${ }^{*} \mathrm{P}<0.05$, vs. NC group. (D) Changes in the expression of NOX4 in the presence of VAS2870 (1, 3 or $\left.5 \mu \mathrm{M}\right)$ with TGF- $\beta 2$ (5 $\left.\mathrm{ng} / \mathrm{ml}\right)$ for 24 h. ${ }^{*} \mathrm{P}<0.05$, vs. TGF- $\beta$ group; ${ }^{\text {P }}<<0.05$, vs. NC group. TGF- $\beta 2$, transforming growth factor- $\beta 2$; NOX4, NADPH oxidase 4 ; PCR, polymerase chain reaction; NC, normal control.

ice-cold ethanol at $4^{\circ} \mathrm{C}$ overnight. The cells were then washed twice with PBS, resuspended in 500- $\mu$ 1 PBS containing $100 \mu \mathrm{g} / \mathrm{ml}$ propidium iodide (Sigma-Aldrich; Merck KGaA) and $100 \mu \mathrm{g} / \mathrm{ml}$ RNase A (Sigma-Aldrich; Merck KGaA), and incubated in the dark for 20-40 min. Finally, cell cycle distribution was detected by flow cytometry at $-24^{\circ} \mathrm{C}$, and the cells were analyzed using a FACSCalibur with FACSort CellQuest v6.0 software (BD Biosciences, Franklin Lakes, NJ, USA).

Immunofluorescence staining. The cells grown on $8 \times 8 \mathrm{~mm}^{2}$ poly-L-lysine-coated coverslips in 24-well plates were starved overnight and then treated with $5 \mathrm{ng} / \mathrm{ml}$ TGF- $\beta 2$ and $5 \mu \mathrm{M}$ VAS2870. After $24 \mathrm{~h}$, the cells were fixed with $4 \%$ paraformaldehyde for $30 \mathrm{~min}$ and washed three times with PBS. The cells were then permeabilized with $0.3 \%$ Triton X-100 for $20 \mathrm{~min}$ at room temperature, and slides were blocked in goat serum(Boster Biological Technology, Pleasanton, CA, USA) for $1 \mathrm{~h}$, followed by overnight incubation at $4^{\circ} \mathrm{C}$ with the following primary antibodies: Monoclonal rabbit anti-human $\alpha$-smooth muscle actin (SMA; 1:200; cat. no. ab124964; Abcam, Cambridge, MA, USA) and monoclonal rabbit anti-human E-cadherin (1:200; cat. no. ab53226; Abcam). Following washing with PBS extensively, the cells were exposed to the fluorescent secondary antibodies, goat anti-rabbit Cy3 (1:10,000; cat. no. CW0114S) and goat anti-rabbit FITC (1:10,000; cat. no. CW0159S) from
CWBio (Beijing, China), in the dark for $30 \mathrm{~min}$. The coverslips were washed again, mounted with DAPI for $5 \mathrm{~min}$, and observed under a fluorescence microscope (DP71; Olympus, Tokyo, Japan).

Western blot analysis. The cells were lysed in RIPA buffer (Sigma-Aldrich; Merck KGaA) supplemented with $1 \%$ protease inhibitor cocktail (Roche Diagnostics, Basel, Switzerland). The proteins (20 $\mu \mathrm{g}$ per lane) were separated using sodium dodecyl sulfate polyacrylamide gel electrophoresis (8-10\% gel) and transferred onto polyvinylidene difluoride membranes. Protein concentration was determined using the BCA kit (Beyotime Institute of Biotechnology, Haimen, China). The membranes were blocked in tris-buffered saline with $1 \%$ Tween-20 (TBST) containing $8 \%$ skim milk at room temperature for $2 \mathrm{~h}$, and incubated with the following primary antibodies: Monoclonal rabbit anti-human cyclin D1 (1:20,000; cat. no. ab134175), monoclonal anti-E-cadherin (1:1,000; cat. no. ab40772), monoclonal anti-NOX4 (1:1,000; cat. no. ab32419) and monoclonal anti- $\alpha$-SMA (1:1,000; cat. no. ab124964), all from Abcam, in a sealed bag overnight at $4^{\circ} \mathrm{C}$ and the membranes were then washed three times for $10 \mathrm{~min}$ each with TBS. The membranes were then incubated with horseradish peroxidase (HRP)-conjugated secondary antibodies (1:100,000; goat polyclonal anti-rabbit 

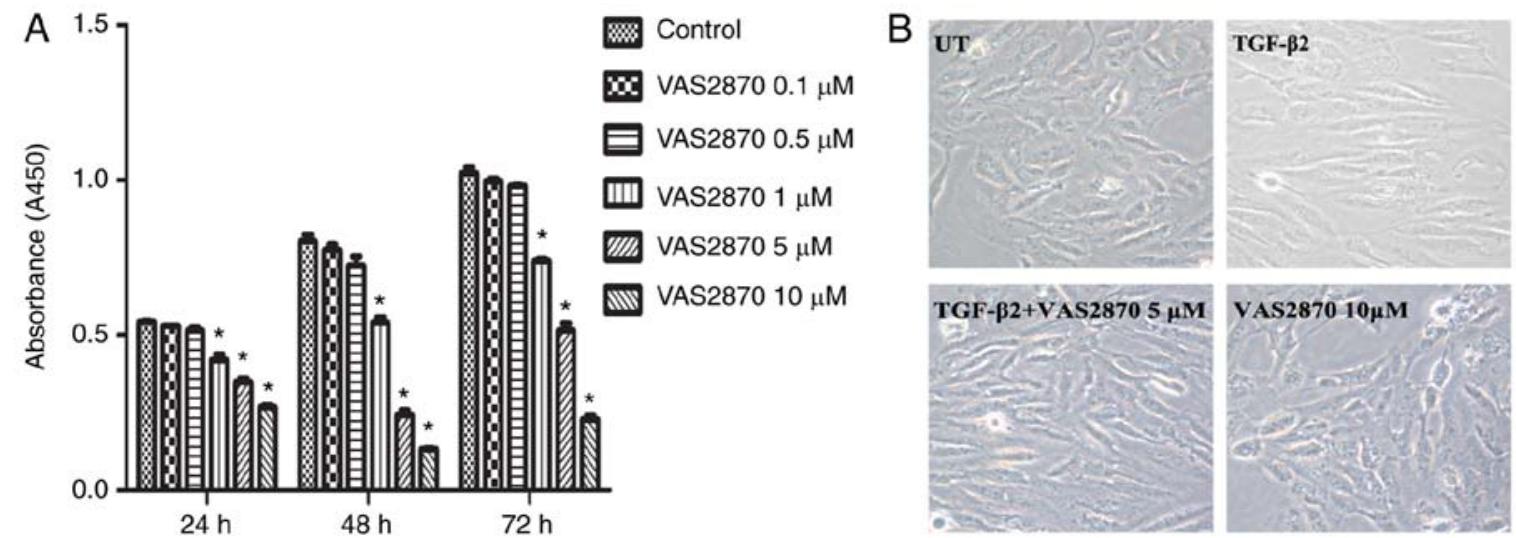

Figure 2. Effect of VAS2870 on RPE cell viability. (A) RPE cells were treated with VAS2870 at different concentrations for 24,48 or $72 \mathrm{~h}$, and cell viability was analyzed. " $\mathrm{P}<0.05$, vs. control group. (B) Images of cells in the presence of VAS2870 at $10 \mu \mathrm{M}$, which caused significant cell death (magnification, $\mathrm{x} 200$ ). RPE cell, retinal pigment epithelial cell.

secondary antibody (IgG-HRP; cat. no. ab6721; Abcam) for $2 \mathrm{~h}$ at room temperature, washed three times with TBST for 15 min each, and subjected to chemiluminescence detection with ECL substrate solution (Genshare Biological, Shaanxi, China) for $2 \mathrm{~min}$. Subsequently, the membranes were placed in a LAS-3000 FujiFilm intelligent dark box. The illuminated bands were detected, and images were captured using Image reader LAS-3000 software 8.0 (Fujifilm Holdings Corporation, Tokyo, Japan). Three independent experiments were performed.

Statistical analysis. All data are presented as the mean \pm standard deviation. Statistical analyses were performed using SPSS version 18.0 for Windows (SPSS, Inc., Chicago, IL, USA). Statistical comparisons were performed using Student's t-test or two-way analysis of variance followed by ANOVA analysis (followed by Tukey's post hoc test) for multiple comparisons. $\mathrm{P}<0.05$ was considered to indicate a statistically significant difference.

\section{Results}

VAS2870 inhibits the expression of NOX4 in TGF- $\beta 2$-treated RPE cells. The effects of VAS2870 on the expression of NOX4 following TGF- $\beta 2$-induced EMT in ARPE-19 cells were determined by western blot analysis. Specifically, the expression of NOX4 was assessed at different time points $(0,4,6,8$ and $12 \mathrm{~h})$ following TGF- $\beta 2(5 \mathrm{ng} / \mathrm{ml})$ stimulation. The expression of NOX4 was initially induced at $4 \mathrm{~h}$ following TGF- $\beta$ treatment and expression was most pronounced at $8 \mathrm{~h}$ (Fig. 1A). In addition, in the RPE cells at $8 \mathrm{~h}$, the mRNA levels of $N O X 4$ were highest, compared with the expression of NOX1 and NOX2 (Fig. 1B). When treated with different concentrations of TGF- $\beta 2$, the protein expression of NOX4 was significantly increased, compared with the levels in the normal control group (Fig. 1C). In addition, the upregulation of NOX4 induced by TGF- $\beta 2$ was significantly inhibited by VAS2870 (Fig. 1D). These results suggested that VAS2870 sufficiently inhibited the TGF- $\beta$ dependent expression of NOX in a dose-dependent manner.

Effects of VAS2870 on RPE cell viability. The effects of VAS2870 on RPE cell viability were examined using different concentrations of VAS2870 for 24,48 and $72 \mathrm{~h}$. As indicated in Fig. 2, VAS2870 treatment resulted in significant inhibitory effects on cell growth in a concentration-dependent manner (Fig. 2A). The viability of cells treated with $10 \mu \mathrm{M}$ VAS2870 was significantly lower, compared with that in cells treated with 1 and $5 \mu \mathrm{M}$ VAS2870 at all three time points. To determine whether the growth inhibitory effect was due to VAS2870-induced cell death, the morphology of cells was evaluated. The results revealed that cells in the normal group were spindle-shaped with oval nuclei and visible black particles in the cytoplasm. By contrast, in the TGF- $\beta 2$ group, the cells were elongated, whereas $5 \mu \mathrm{M}$ VAS2870 did not affect cell survival. However, treatment with $10 \mu \mathrm{M}$ VAS2870 for $24 \mathrm{~h}$ resulted in an increased number of dead cells, which had lost their original spindle shape and in which cytochrome had diffused into the extracellular matrix (Fig. 2B). These results indicated that the growth inhibitory effects of low concentrations of VAS2870 (1 and $5 \mu \mathrm{M})$ were predominantly caused by the suppression of cell proliferation, whereas a higher concentration $(10 \mu \mathrm{M})$ resulted in cell death. Therefore, 1 and $5 \mu \mathrm{M}$ VAS2870 was used for subsequent experiments.

VAS2870 inhibits TGF 32 -induced cell migration. TGF 32 -mediated cell migration in RPE cells has been implicated in the development of PVR (21). Therefore, the present study examined whether VAS2870 suppressed this event. As shown in Fig. 3A, TGF 32 significantly enhanced cell migration, compared with that in the control group. The distance covered by cells treated with VAS2870 $(5 \mu \mathrm{M})$ was shorter than that in the TGF- $\beta 2$-treated group at $24 \mathrm{~h}$ (Fig. 3B). By $48 \mathrm{~h}$, the wound had healed in the TGF $\beta 2$ group; however, at the same time point, a gap there remained in the VAS2870 group (Fig. 3C). These data demonstrated that pretreatment with VAS2870 inhibit TGF- $\beta$-dependent migration at a concentration of $5 \mu \mathrm{M}$.

VAS2870 inhibits the proliferation of RPE cells by inducing $G_{1}$-phase cell cycle arrest. The present study also evaluated the effects of VAS2870 on cell cycle arrest (Fig. 4A). Upon culture with different concentrations of $\operatorname{VAS} 2870(0,1$, 3 and $5 \mu \mathrm{M}$ ) for $24 \mathrm{~h}$, an accumulation of RPE cells in the 


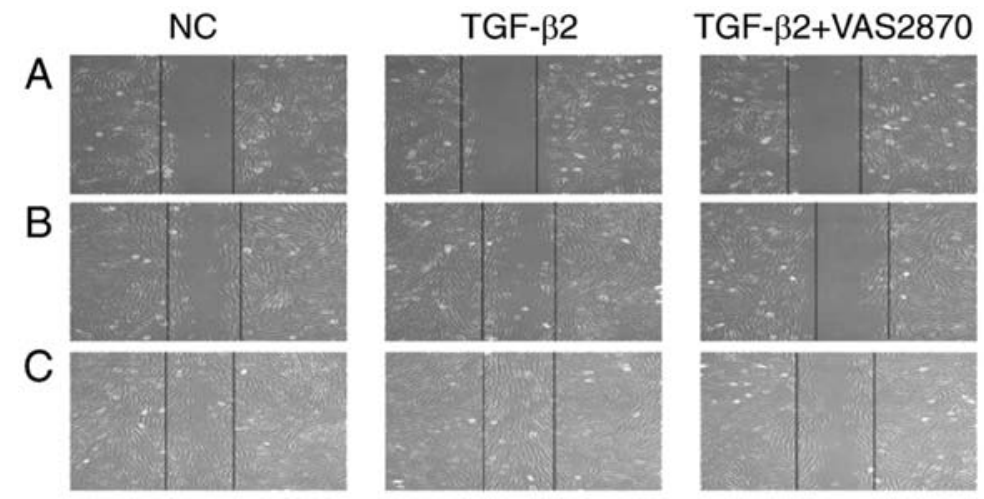

Figure 3. Effects of VAS2870 on TGF 32 -induced wound healing in ARPE-19 cell monolayers (magnification, x50). (A) Wounds were introduced in the center of the cell monolayers at $0 \mathrm{~h}$. (B) Distance traveled by cells at $24 \mathrm{~h}$. The remaining gap in the VAS2870 group was compared with that in the TGF- $\beta 2$-induced migration group. (C) Wound healing in the TGF- $\beta 2$ group and VAS2870 group at $48 \mathrm{~h}$. TGF- $\beta 2$, transforming growth factor- $\beta 2$; NC, normal control group.
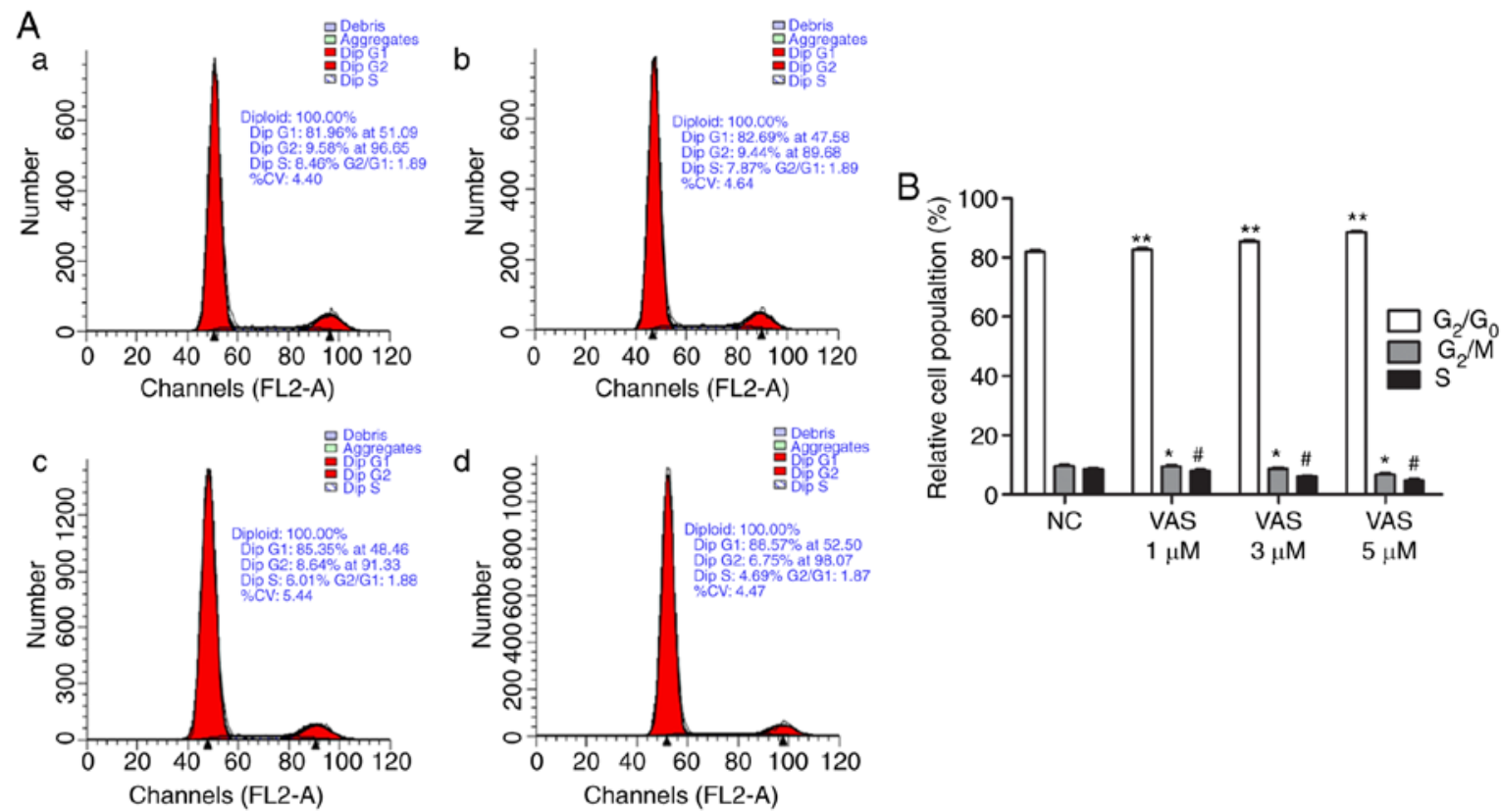

Figure 4. Effects of VAS2870 on cell cycle distribution of RPE cells. (A) Representative images of flow cytometry of cells in the four groups: (a) NC group, and (b) 1 , (c) 3 and (d) $5 \mu \mathrm{M}$ VAS2870 groups. (B) Cell cycle distribution of RPE cells in the four groups. Group B, C and $\mathrm{D},{ }^{* *} \mathrm{P}<0.05 \mathrm{G}_{1} / \mathrm{G}_{0}$ vs. NC, ${ }^{*} \mathrm{P}<0.05$ $\mathrm{G}_{2} / \mathrm{M}$ vs. NC, "P $<0.05 \mathrm{~S}$ vs. NC. RPE cell, retinal pigment epithelial; NC, normal control.
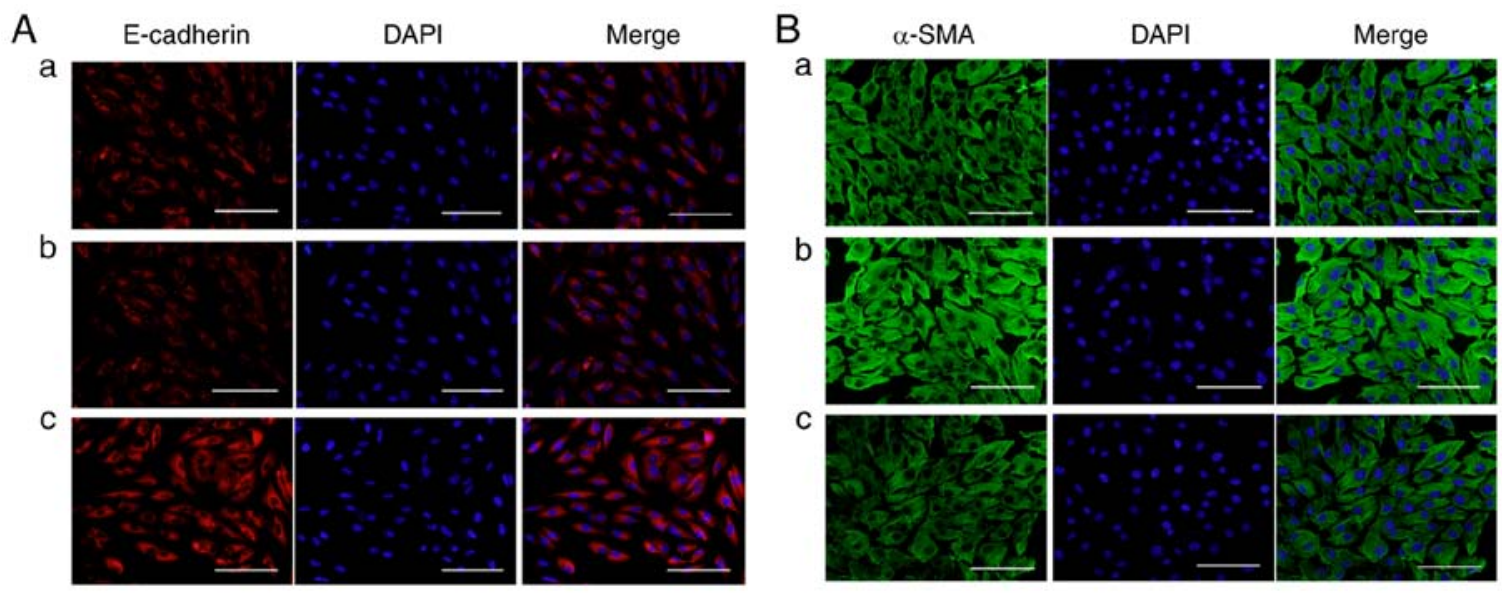

Figure 5. Expression of E-cadherin and $\alpha$-SMA in RPE cells. Immunofluorescence staining for (A) E-cadherin (red) in RPE cells in the (a) normal control group, (b) TGF- $\beta 2$-treated group, and (c) VAS2870 group exposed to TGF- $\beta 2$. (B) Expression of $\alpha$-SMA (green) in RPE cells in the (a) normal control group, (b) TGF- $\beta 2$-treated group and (c) VAS2870 group exposed to TGF- $\beta 2$. Representative images are shown (magnification, $\mathrm{x} 200 ;$ Scale bar=100 $\mu \mathrm{m}$ ). TGF- $\beta 2$, transforming growth factor- $\beta 2 ; \alpha$-SMA, $\alpha$-smooth muscle actin. 


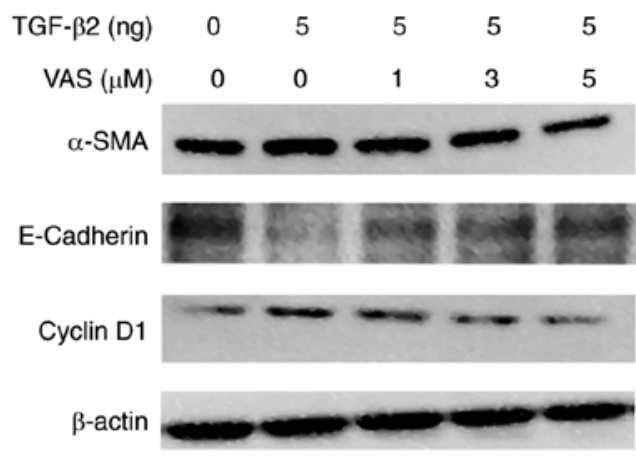

E-cadherin

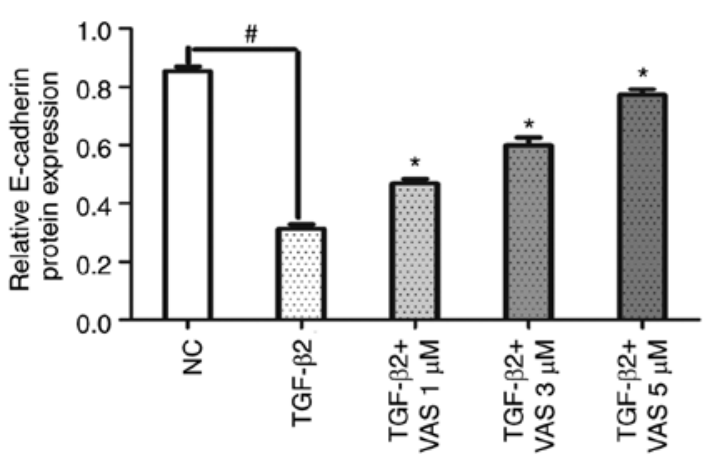

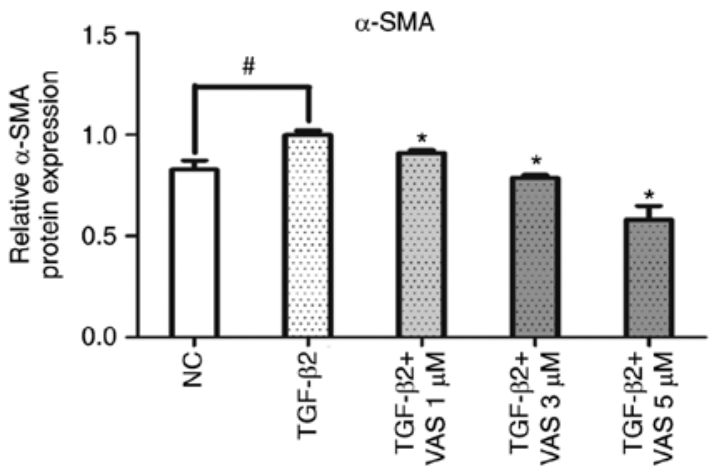

Cyclin D1

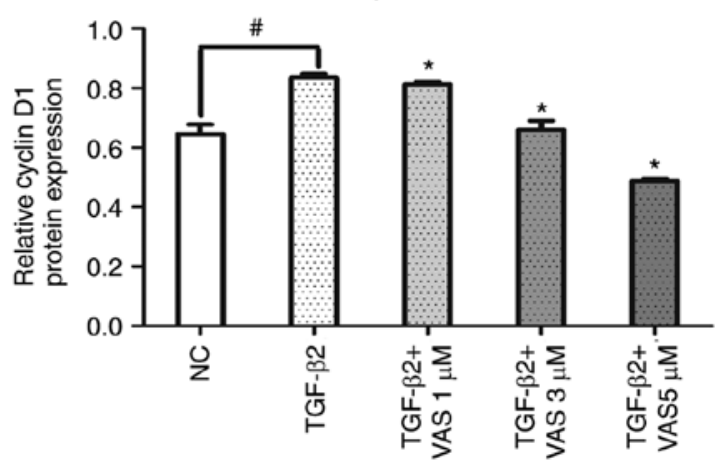

Figure 6. Results of western blot analysis showing the effects of the inhibition of NOX4 on the protein expression of $\alpha$-SMA, E-cadherin and cyclin D1 in TGF- $\beta 2$-exposed RPE cells. ${ }^{~} \mathrm{P}<0.05$ TGF- $\beta$ group vs. NC group, and ${ }^{*} \mathrm{P}<0.05$ TGF- $\beta+V A S 2870$ vs. TGF- $\beta$ group for the protein expression of $\alpha$-SMA, E-cadherin and cyclin D1. NOX4, NADPH oxidase 4; TGF- $\beta 2$, transforming growth factor- $\beta 2 ; \alpha$-SMA, $\alpha$-smooth muscle actin; VAS, VAS2870; NC, normal control group.

$\mathrm{G}_{0} / \mathrm{G}_{1}$ phase and a decrease in the number of cells in the $\mathrm{S}$ and $\mathrm{G}_{2} / \mathrm{M}$ phases were noted compared with those in the normal control group (Fig. 4B). These findings indicated that VAS2870 inhibited the proliferation of RPE cells via $G_{1}$ phase cell cycle arrest.

VAS2870 prevents TGF- $\beta 2$-induced EMT in RPE cells. To investigate whether VAS2870 affects EMT in RPE cells, the present study examined the expression of E-cadherin (an epithelial marker) and $\alpha$-SMA (a mesenchymal marker) following treatment with VAS2870. The expression and distribution of E-cadherin and $\alpha$-SMA in RPE cells was also detected by immunofluorescence staining. Under physiological conditions, E-cadherin was expressed in the cell membrane (Fig. 5Aa) whereas, in the presence of TGF- $\beta 2$, staining for E-cadherin in the VAS2870 group was more marked, compared with that in the TGF- $\beta 2$ group (Fig. $5 \mathrm{Ab}$ and $\mathrm{c}$ ). Under physiological conditions, $\alpha$-SMA was localized to the cytoplasm in RPE cells (Fig. 5Ba), whereas staining for $\alpha$-SMA was diffuse and enhanced in the TGF- $\beta 2$ group (Fig. $5 \mathrm{Bb}$ ), compared with that in the VAS2870 group (Fig. 5Bc).

The results of western blot analysis revealed that the expression of $\alpha$-SMA was significantly upregulated and that of E-cadherin was downregulated following treatment with TGF- $\beta 2$ for $24 \mathrm{~h}$, compared with levels in the control group $(\mathrm{P}<0.05$; Fig. 6$)$, indicating that TGF- $\beta 2$ promoted the differentiation of RPE cells. Of note, the differentiation capacity was reduced by VAS2870; treatment significantly reduced the expression of $\alpha$-SMA, compared with that in the TGF- $\beta 2$ group, but increased the expression of E-cadherin in a concentration-dependent manner $(\mathrm{P}<0.05$; Fig. 6). Therefore, these data showed that the NOX inhibitor VAS2870 significantly attenuated TGF- 32 -induced EMT in RPE cells.

To investigate the mechanism associated with cell cycle arrest, the present study examined the effects of the pharmacological inhibition of NOX on the expression of cell cycle-regulated proteins by western blot analysis. As expected, VAS2870 significantly decreased the expression of cyclin D1 in a concentration-dependent manner $(\mathrm{P}<0.05$; Fig. 6). Taken together, these data suggested that VAS2870 suppressed the proliferation of RPE cells by inducing $G_{1}$ phase cell cycle arrest, which occurred through the inhibition of cyclin D1.

In conclusion, the data obtained demonstrated that NOXs are critical for TGF- $\beta$-dependent EMT and migration in RPE cells and modulate signaling pathways, which promote proliferation in these cells.

\section{Discussion}

In the present study, the effects of the novel NOX inhibitor VAS2870 on the expression of NOX4 and the functional effects mediated by growth factors in RPE cells were determined for the first time, to the best of our knowledge. It was demonstrated that the mRNA expression of NOX4 was highest among the NOX homologs analyzed (NOX1 and NOX2) in RPE cells, and that the protein expression of NOX4 was increased 
significantly upon TGF- $\beta 2$ stimulation in these cells. It was also shown that the pan-NOX inhibitor VAS2870 markedly suppressed the TGF- $\beta 2$-induced expression of NOX4, and that RPE cells retained an epithelial-like phenotype following VAS2870 treatment. In addition, VAS2870 suppressed cell proliferation, and TGF- $\beta$-dependent migration and EMT.

The role of NOX as a signaling molecule in cell migration has been reported by several groups. In the present study, it was demonstrated that the NOX inhibitor VAS2870 eliminated TGF- $\beta$-dependent migration in RPE cells in a concentration-dependent manner. These findings are consistent with a previous report demonstrating that this molecule can inhibit TGF- $\beta$-dependent migration in vascular smooth muscle cells (22). In addition, Boudreau et al indicated that NOX4 was involved in TGF- $\beta$-induced lung and breast epithelial cell migration (23).

However, the role of TGF- $\beta$ in cell proliferation remains to be fully elucidated. Treatment with VAS2870 inhibited cell cycle progression through the $G_{1}$ phase, as determined by flow cytometry. Several studies have shown that other NOX inhibitors reduce proliferation in various cell types. For example, in pulmonary vascular cells, hypoxia-induced proliferation was significantly suppressed by the inhibition of NOX activity using the NOX inhibitor GKT137831 (24). In addition, NOX4 was shown to mediate proliferation in response to TGF- $\beta$ in human pulmonary artery smooth muscle cells (25).

Notably, the present study showed that VAS2870 reversed TGF- $\beta 2$-induced EMT in RPE cells. During this process, expression of the epithelial differentiation marker E-cadherin in these cells was lost and the expression of mesenchymal marker $\alpha$-SMA increased (26,27). E-cadherin, a cell-cell adhesion molecule, is located at the cell-cell boundary of the normal epithelium (28) and is associated with invasion and metastasis in cancer (29). The present study showed that this protein was upregulated in the membrane of RPE cells, indicating that it can act as an intercellular adhesion molecule. Consistent with these findings, angiotensin II-induced hepatocyte EMT was previously reported to be inhibited by NOX4 small interfering (si)RNA in hepatocytes (30). In the lens capsule, VAS2870 was shown to inhibit the expression of NOX4, which is the only NOX isoform expressed during TGF- $\beta 2$-induced EM; those cells which survived following VAS2870 treatment retained an epithelial-like phenotype, indicating that VAS2870 reversed EMT through the inhibition of NOX4 (31).

NOXs have been shown to transmit downstream TGF- $\beta$ signaling. In skeletal muscle cells, TGF- $\beta$ induces its own expression, and the NOX pharmacological inhibitor apocynin has been shown to inhibit this process (32). By contrast, in liver tumor cells, VAS2870 effectively attenuates serum-dependent growth and the phosphorylation of AKT and extracellular signal-regulated kinase (33). In addition, Boudreau et al demonstrated that silencing NOX4 prevented cell migration mediated by the small mothers against decapentaplegic (Smad) signaling pathway in breast cancer cells (34). In the investigation of ocular disease, NOX4 was shown to be required for complete activation of mitogen-activated protein kinase (MAPK) signaling upstream of reactive oxygen species in human bronchial epithelial cells during EMT (35). Taken together, these findings suggest that NOX4 may act as a common mediator of these pathways and that redox signaling may serve as a nexus between parallel signaling pathways, including those of Smads and MAPKs.

In conclusion, the results of the present study indicated that the pharmacological inhibition of NOX with VAS2870 effectively impaired the proliferation of RPE cells. VAS2870 treatment also attenuated the migration and EMT induced by TGF- $\beta 2$, a physiological pro-EMT stimulus. Notably, the effects of VAS2870 on NOX enzymes were not isoform-specific, and the final results may have been representative of the combined effects of inhibiting all isoforms expressed in the cells. In RPE cells, other isoforms, including NOX1 and NOX2, were expressed at low levels. In particular, NOX4 appeared to be crucial in RPE cells. Therefore, the pharmacological inhibition of NOX may provide insights into the development of improved treatments for PVR. However, there were limitations to the present study. First, only the biological behaviors of RPE cells following NOX4 inhibition were observed, and the molecular mechanisms responsible for this process were not elucidated. Further experiments are required to examine the efficiency of NOX4 silencing by siRNA, using the same experimental conditions, and to examine the effects of VAS2870 on other signal transduction pathways, to fully elucidate the complex interactions among these pathways. The pharmacological inhibition of NOX may be a promising therapeutic approach for proliferative retinopathy and for the prevention of secondary PVR.

\section{Acknowledgements}

Not applicable.

\section{Funding}

The present study was supported by the Shannxi Provincial Natural Science Foundation of China (grant no.2014JM2-8190).

\section{Availability of data and materials}

All data analyzed during this study are included in this published article.

\section{Author's contributions}

JY and QY conceived and designed the experiments. JY performed the experiments. JL, QW, YX and ZZ contributed reagents and materials. All authors read and approved the final manuscript.

\section{Ethics approval and consent to participate}

Not applicable.

\section{Consent for publication}

Not applicable.

\section{Competing interests}

The authors declare they have no competing interests. 


\section{References}

1. Ho PC and McMeel JW: Retinal detachment with proliferative vitreoretinopathy: Surgical results with scleral buckling, closed vitrectomy, and intravitreous air injection. Br J Ophthalmol 69: 584-587, 1985.

2. KrollP,Rodrigues EB and Hoerle S: Pathogenesis and classification of proliferative diabetic vitreoretinopathy. Ophthalmologica 221: 78-94, 2007.

3. Tosi GM, Marigliani D, Romeo N and Toti P: Disease pathways in proliferative vitreoretinopathy: An ongoing challenge. J Cell Physiol 229: 1577-1583, 2014

4. Cui JZ, Chiu A, Maberley D, Ma P, Samad A and Matsubara JA: Stage specificity of novel growth factor expression during development of proliferative vitreoretinopathy. Eye 21: 200-208, 2007.

5. Pastor JC, de la Rúa ER and Martín F: Proliferative vitreoretinopathy: Risk factors and pathobiology. Prog Retin Eye Res 21 127-144, 2002

6. Grisanti S and Guidry C: Transdifferentiation of retinal pigment epithelial cells from epithelial to mesenchymal phenotype. Invest Ophthalmol Vis Sci 36: 391-405, 1995.

7. Pennock S, Haddock LJ, Eliott D, Mukai S and Kazlauskas A: Is neutralizing vitreal growth factors a viable strategy to prevent proliferative vitreoretinopathy? Prog Retin Eye Res 40: 16-34, 2014.

8. Lassègue $\mathrm{B}$ and Clempus RE: Vascular NAD $(\mathrm{P}) \mathrm{H}$ oxidases: Specific features, expression, and regulation. Am J Physiol Regul Integr Comp Physiol 285: R277-R297, 2003.

9. Brown DI and Griendling KK: Nox proteins in signal transduction. Free Radic Biol Med 47: 1239-1253, 2009.

10. Kita T,Hata Y, Kano K, Miura M, Nakao S, Noda Y, Shimokawa H and Ishibashi T: Transforming growth factor-beta 2 and connective tissue growth factor in proliferative vitreoretinal diseases: Possible involvement of hyalocytes and therapeutic potential of Rho kinase inhibitor. Diabetes 56: 231-238, 2007.

11. Xu J, Lamouille S and Derynck R: TGF-beta-induced epithelial to mesenchymal transition. Cell Res 19: 156-172, 2009.

12. Qiu Y, Tao L, Lei C, Wang J, Yang P, Li Q and Lei B Downregulating p22phox ameliorates inflammatory response in Angiotensin II-induced oxidative stress by regulating MAPK and NF- $\kappa$ B pathways in ARPE-19 cells. Sci Rep 5: 14362, 2015.

13. Kim JH, Park S, Chung H and Oh S: Wnt5a attenuates the pathogenic effects of the Wnt/beta-catenin pathway in human retinal pigment epithelial cells via down-regulating $\beta$-catenin and Snail BMB Rep 48: 525-530, 2015.

14. Michaeloudes C, Sukkar MB, Khorasani NM, Bhavsar PK and Chung KF: TGF- $\beta$ regulates Nox 4, MnSOD and catalase expression, and IL-6 release in airway smooth muscle cells. Am J Physiol Lung Cell Mol Physiol 300: L295-L304, 2011.

15. Li S, Tabar SS, Malec V, Eul BG, Klepetko W, Weissmann N, Grimminger F, Seeger W, Rose F and Hänze J: NOX4 regulates ROS levels under normoxic and hypoxic conditions, triggers proliferation, and inhibits apoptosis in pulmonary artery adventitial fibroblasts. Antioxid Redox Signal 10: 1687-1698, 2008

16. Pan X, Dai Y, Li X, Niu N, Li W, Liu F, Zhao Y and Yu Z: Inhibition of arsenic-induced rat liver injury by grape seed exact through suppression of NADPH oxidase and TGF- $\beta /$ Smad activation. Toxicol Appl Pharmacol 254: 323-331, 2011.

17. Lapperre TS, Jimenez LA, Antonicelli F, Drost EM, Hiemstra PS, Stolk J, MacNee W and Rahman I: Apocynin increases glutathione synthesis and activates AP-1 in alveolar epithelial cells. FEBS Lett 443: 235-239, 1999.

18. Engels F, Renirie BF, Hart BA, Labadie RP and Nijkamp FP: Effects of apocynin, a drug isolated from the roots of Picrorhiza kurroa, on arachidonic acid metabolism. FEBS Lett 305 254-256, 1992.

19. Majander A, Finel M and Wikström M: Diphenyleneiodonium inhibits reduction of iron-sulfur clusters in the mitochondrial NADH-ubiquinone oxidoreductase (Complex I). J Biol Chem 269: 21037-21042, 1994.

20. Livak KJ and Schmittgen TD: Analysis of relative gene expression data using real-time quantitative PCR and the $2^{-\Delta \Delta C \mathrm{~T}}$ method. Methods 25: 402-408, 2001.
21. Ishikawa K, He S, Terasaki H, Nazari H, Zhang H, Spee C, Kannan R and Hinton DR: Resveratrol inhibits epithelial-mesenchymal transition of retinal pigment epithelium and development of proliferative vitreoretinopathy. Sci Rep 5: 16386, 2015.

22. ten Freyhaus H, Huntgeburth M, Wingler K, Schnitker J, Bäumer AT, Vantler M, Bekhite MM, Wartenberg M, Sauer H and Rosenkranz S: Novel Nox inhibitor VAS2870 attenuates PDGF-dependent smooth muscle cell chemotaxis, but not proliferation. Cardiovasc Res 71: 331-341, 2006.

23. Boudreau HE, Casterline BW, Burke DJ and Leto TL: Wild-type and mutant p53 differentially regulate NADPH oxidase 4 in TGF- $\beta$-mediated migration of human lung and breast epithelial cells. Br J Cancer 110: 2569-2582, 2014.

24. Green DE,Murphy TC,Kang BY,KleinhenzJM,Szyndralewiez C, Page P, Sutliff RL and Hart CM: The Nox4 inhibitor GKT137831 attenuates hypoxia-induced pulmonary vascular cell proliferation. Am J Respir Cell Mol Biol 47: 718-726, 2012.

25. Martin-Garrido A, Brown DI, Lyle AN, Dikalova A, Seidel-Rogol B, Lassègue B, San Martín A and Griendling KK: NADPH oxidase 4 mediates TGF- $\beta$-induced smooth muscle $\alpha$-actin via p38MAPK and serum response factor. Free Radic Biol Med 50: 354-362, 2011.

26. Tobar N, Toyes M, Urra C, Méndez N, Arancibia R, Smith PC and Martínez J: c-Jun N terminal kinase modulates NOX-4 derived ROS production and myofibroblasts differentiation in human breast stromal cells. BMC Cancer 14: 640, 2014.

27. OkaH, Shiozaki H, KobayashiK, Inoue M, Tahara H,Kobayashi T, Takatsuka Y, Matsuyoshi N, Hirano S, Takeichi M, et al: Expression of E-cadherin cell adhesion molecules in human breast cancer tissues and its relationship to metastasis. Cancer Res 53: 1696-1701, 1993.

28. Li H, Wang H, Wang F, Gu Q and Xu X: Snail involves in the transforming growth factor $\beta 1$-mediated epithelial-mesenchymal transition of retinal pigment epithelial cells. PLoS One 6: e23322, 2011.

29. Palma-Nicolás JP and López-Colomé AM: Trombin induces slug-mediated E-cadherin transcriptional repression and the parallel up-regulation of $\mathrm{N}$-cadherin by a transcription-independent mechanism in RPE cells. J Cell Physiol 228: 581-589, 2013.

30. Zhang LL, Huang S, Ma XX, Zhang WY, Wang D, Jin SY, Zhang YP, Li Y and Li X: Angiotensin(1-7) attenuated angiotensin II-induced hepatocyte EMT by inhibiting NOX-derived $\mathrm{H}_{2} \mathrm{O}_{2}$-activated NLRP3 inflammasome/IL-1 $\beta / \mathrm{Smad}$ circuit. Free Radic Biol Med 97: 531-543, 2016.

31. Das SJ, Lovicu FJ and Collinson EJ: Nox4 plays a role in TGF- $\beta$-dependent lens epithelial to mesenchymal transition. Invest Ophthalmol Vis Sci 57: 3665-3673, 2016.

32. Abrigo J, Morales MG, Simon F, Cabrera D, Di Capua G and Cabello-Verrugio C: Apocynin inhibits the upregulation of TGF- $\beta 1$ expression and ROS production induced by TGF- $\beta$ in skeletal muscle cells. Phytomedicine 22: 885-893, 2015.

33. Sancho $P$ and Fabregat I: The NADPH oxidase inhibitor VAS 2870 impairs cell growth and enhances TGF- $\beta$-induced apoptosis of liver tumor cells. Biochem Pharmacol 81: 917-924, 2011.

34. Boudreau HE, Casterline BW, Rada B, Korzeniowska A and Leto TL: Nox4 involvement in TGF-beta and SMAD3-driven induction of the epithelial-to-mesenchymal transition and migration of breast epithelial cells. Free Radic Biol Med 53: 1489-1499, 2012.

35. Ge A, Ma Y, Liu YN, Li YS, Gu H, Zhang JX, Wang QX, Zeng XN and Huang M: Diosmetin prevents TGF- $\beta 1$-induced epithelial-mesenchymal transition via ROS/MAPK signaling pathways. Life Sci 153: 1-8, 2016.

This work is licensed under a Creative Commons Attribution-NonCommercial-NoDerivatives 4.0 International (CC BY-NC-ND 4.0) License. 